\title{
Physicochemical study of diethylmethylammonium methanesulfonate under anhydrous conditions
}

\author{
Hailong Pan, ${ }^{1}$ Pieter Geysens, ${ }^{2}$ Tristan Putzeys, ${ }^{1}$ Alessia Gennaro, ${ }^{1}$ Yingting Yi, ${ }^{1}$ \\ Hua Li, ${ }^{3}$ Rob Atkin, ${ }^{3}$ Koen Binnemans, ${ }^{2}$ Jiangshui Luo ${ }^{1,4, a)}$ and Michael \\ Wübbenhorst ${ }^{1}$
}

\section{AFFILIATIONS}

${ }^{1}$ Laboratory for Soft Matter and Biophysics, Department of Physics and Astronomy, KU Leuven, Leuven, 3001, Belgium.

${ }^{2}$ Department of Chemistry, KU Leuven, 3001 Leuven, Belgium.

${ }^{3}$ School of Molecular Sciences, University of Western Australia, 35 Stirling Highway, Perth, WA 6009, Australia.

${ }^{4}$ College of Materials Science and Engineering, Sichuan University, 610065, Chengdu, China

a) Authors to whom correspondence should be addressed:

Jiangshui.Luo@kuleuven.be; Jiangshui.Luo@scu.edu.cn

\begin{abstract}
The protic ionic liquid diethylmethylammonium methanesulfonate ([DEMA][OMs]) was analyzed in depth by differential scanning calorimetry (DSC), nuclear magnetic resonance (NMR) spectroscopy, Fourier transform infrared (FT-IR) spectroscopy,
\end{abstract}


Raman spectroscopy and broadband dielectric spectroscopy (BDS) under anhydrous conditions. Karl Fischer titration, NMR and FT-IR spectra confirmed the high purity of $[\mathrm{DEMA}][\mathrm{OMs}]$. The melting point $\left(37.7^{\circ} \mathrm{C}\right)$ and the freezing point $\left(14.0{ }^{\circ} \mathrm{C}\right)$ obtained by DSC agree well with the values determined by BDS $\left(40.0{ }^{\circ} \mathrm{C}\right.$ and 14.0 $\left.{ }^{\circ} \mathrm{C}\right)$. The dc conductivity $\left(\sigma_{\mathrm{dc}}\right)$ above the melting/freezing point obeys Vogel-Fulcher-Tammann (VFT) equation well and thus the proton conduction in [DEMA] $[\mathrm{OMs}]$ is assumed to be dominated by the vehicle mechanism. In contrast, the $\sigma_{\mathrm{dc}}$ below the melting/freezing point can be fitted by the Arrhenius equation separately and therefore the proton conduction is most likely governed by the proton-hopping mechanism. The non-negligible influence of previously reported low water contents on the physicochemical properties of [DEMA][OMs] is found, indicating the importance of reducing water content as much as possible for the study of "intrinsic" properties of protic ionic liquids.

\section{INTRODUCTION}

Recently, protic ionic liquids (PILs), which are prepared by proton transfer from a Brønsted acid to a Brønsted base, have attracted research attention because of their excellent physicochemical properties which can include relatively low volatility, high thermal stability and high conductivity. ${ }^{1-5}$ For these reasons PILs are widely used in fuel cells, sensors and supercapacitors, as well as in other electrochemical devices. ${ }^{6-10}$ PILs have proton-donor and proton-acceptor sites, which form a hydrogen-bonded network. ${ }^{2,11}$ Therefore, comprehensive studies of typical PILs will offer more knowledge about them.

The PIL [DEMA][OMs] has a $\sigma_{\mathrm{dc}}$ of $2.22 \times 10^{-2} \mathrm{~S} \mathrm{~cm}^{-1}$ at $120{ }^{\circ} \mathrm{C}$ and was first reported by Nakamoto and Watanabe in $2007 .{ }^{12}$ This compound has been investigated 
as electrolytes or green solvents. ${ }^{12-21}$ Overall, the related studies can be divided into three groups. (1) The effect of the water content on the fundamental physical and chemical properties. ${ }^{13-16}$ For example, Schubert et al. studied the influence of water on the thermodynamic properties (e.g. vapor pressures, heat capacities, densities, and viscosities) of the binary mixtures of water and [DEMA][OMs]. ${ }^{13}$ Martinelli et al. reported that the added water increased the self-diffusion of cations and anions and interacted primarily with the anion and slightly affected the ionicity of $[$ DEMA $][\mathrm{OMs}] .{ }^{16}$ (2) The applications of $[\mathrm{DEMA}][\mathrm{OMs}] .{ }^{17-19}$ For instance, Atilhan et al. showed that [DEMA][OMs] is suitable for pressure driven $\mathrm{CO}_{2}$ capture processes that might lead to reduction in solvent regeneration cost. ${ }^{17}$ In addition, [DEMA][OMs] was employed to fill nano-pores of silica to enhance the ionic mobility. ${ }^{19}$ (3) Studies of the $\sigma_{\mathrm{dc}}$ and proton conduction mechanisms. ${ }^{19-21}$ Martinelli et $a l$. found that the $\sigma_{\mathrm{dc}}$ of bulk [DEMA][OMs] obeys a VFT dependence, and that the charge transport mechanism is strongly associated with the vehicle mechanism. ${ }^{19}$ Yarger et al. measured the ionicity and transport properties of a series of diethylmethylamine based PILs by nuclear magnetic resonance (NMR) spectroscopy, and concluded that the gas phase proton affinity is a better predictor of ionicity than the commonly used aqueous $\Delta \mathrm{p} K{ }_{\mathrm{a}}{ }^{20}$ Additionally, Krishnan et al. reported the proton transport mechanism (vehicle mechanism) of [DEMA][OMs] above the melting point. $^{21}$

However, to the best of our knowledge, there have been no reports on the dielectric properties of [DEMA][OMs] and its proton conduction mechanisms below the melting/freezing point, restricting further understanding and applications of this PIL and its analogues. On other hand, the majority of previous reports ${ }^{13-19}$ used commercial [DEMA][OMs] (water content: around $7000 \mathrm{ppm}^{18}$ ) as received without 
further purification while other reports also indicated significant water content $(e . g$. about $2000 \mathrm{ppm}^{21}$ ). Nevertheless, the influence of even lower water content on the physicochemical properties of [DEMA][OMs] has so far been neglected.

BDS can probe the electrical properties, (dielectric) relaxation phenomena and thermal phase transitions in a very wide range of temperatures and frequencies. ${ }^{22-24}$ Dielectric spectra can be represented in different ways, such as the (complex) permittivity, electrical conductivity spectra and the electric modulus, of which the electrical conductivity has the advantage of revealing the proton conduction mechanisms. $^{22-24}$

In this paper, the thermal, spectroscopic and dielectric properties as well as the proton conduction mechanism of pure [DEMA][OMs] with an extremely low water content (98 ppm) was investigated in depth using DSC, NMR, FT-IR, Raman spectroscopy, and BDS (over a broad range of temperatures and frequencies). It is found that even a very low water content reported in the literature can still have non-negligible influence on the physicochemical properties of protic ionic liquids, indicating the importance of reducing water content as much as possible for the study of "intrinsic" properties of protic ionic liquids. The dielectric properties of $[\mathrm{DEMA}][\mathrm{OMs}]$ and the proton conduction mechanisms below the melting/freezing point (in the solid state) are also investigated, which is a complement to previous studies.

\section{EXPERIMENTAL DETAILS}

\section{A. Materials}

[DEMA] $[\mathrm{OMs}]\left(\left[\left(\mathrm{C}_{2} \mathrm{H}_{5}\right)_{2} \mathrm{CH}_{3} \mathrm{NH}\right]^{+} \cdot\left[\mathrm{CH}_{3} \mathrm{SO}_{3}\right]^{-}\right)$was purchased from Iolitec Ionic Liquids Technologies GmbH (Heilbronn, Germany). [DEMA][OMs] was dried on a 
Schlenk line in vacuo at $150{ }^{\circ} \mathrm{C}$ for $24 \mathrm{~h}$ to remove water and other volatile components. The purified samples were stored in a dry nitrogen environment prior to further characterizations.

\section{B. Water content determination}

The water content of dried [DEMA][OMs] was detected to be 98 ppm using a Mettler-Toledo C30S coulometric Karl Fischer titrator.

\section{Differential scanning calorimetry (DSC)}

DSC measurements were performed on a Mettler-Toledo DSC1 Star using hermetically sealed aluminum sample cups. DSC traces were obtained by performing heating and cooling cycles between $-70{ }^{\circ} \mathrm{C}$ and $200{ }^{\circ} \mathrm{C}$ at a scanning rate of $10{ }^{\circ} \mathrm{C}$ $\min ^{-1}$. Three consecutive heating/cooling cycles were measured for each test. The first two heating/cooling scans were performed to eliminate the thermal history. The melting point $\left(T_{\mathrm{m}}\right)$ and the freezing point $\left(T_{\mathrm{f}}\right)$ were assigned as the peak temperatures of the corresponding endothermic and exothermic peaks, respectively.

\section{Fourier Transform Infrared (FT-IR) and Raman analysis}

The FT-IR spectrum of [DEMA][OMs] at room temperature was measured between 3500 and $250 \mathrm{~cm}^{-1}$ with a resolution of $2 \mathrm{~cm}^{-1}$ using a Bruker VERTEX 70 FT-IR spectrometer equipped with a Platinum ATR accessory by accumulating 64 scans. Raman spectra between 3500 and $250 \mathrm{~cm}^{-1}$ were collected on the same FT-IR spectrometer Bruker Vertex 70 with a Raman module Bruker RAM II using a 250 $\mathrm{mW}$ laser source $(\lambda=1064 \mathrm{~nm})$ at a resolution of $2 \mathrm{~cm}^{-1}$ with 64 scans.

\section{E. Nuclear magnetic resonance (NMR) measurement}

NMR spectra were measured on a Bruker Avance ${ }^{\mathrm{TM}}$ III $400 \mathrm{MHz}$ spectrometer at 
ambient temperature. $\mathrm{CDCl}_{3}$ was used as the solvent. ${ }^{1} \mathrm{H}-\mathrm{NMR}$ (400 $\mathrm{MHz}$, $\left.\mathrm{CDCl}_{3}\right)$ /ppm: $10.30(\mathrm{~s}, 1 \mathrm{H}) ; 7.30$ (s, $\mathrm{CDCl}_{3}$ solvent residual signal); 3.29-3.07 (m, 4H); 2.9-2.76 (m, 6H); $1.41(\mathrm{t}, J=7.28 \mathrm{~Hz}, 6 \mathrm{H}), 0.00$ (s, TMS reference). ${ }^{13} \mathrm{C}$ NMR (100.61 MHz, $\mathrm{CDCl}_{3}$ )/ppm: 77.20 (solvent residual signal); 50.32 (s); 39.35 (s); 38.88 (s); 9.13 (s); 0.00 (TMS reference).

\section{F. Broadband dielectric spectroscopy (BDS)}

The temperature and the frequency dependence of the complex conductivity of [DEMA][OMs] were studied by means of a Novocontrol BDS spectrometer with an active sample cell based on a high resolution impedance analyzer at frequencies between $421 \mathrm{mHz}$ and $2.5 \mathrm{MHz}$. [DEMA][OMs] was placed in a stainless steel liquid cell and then heated from ambient temperature to $100{ }^{\circ} \mathrm{C}$ to ensure complete filling of the cell. The system was then cooled down to $-100{ }^{\circ} \mathrm{C}$. Afterwards, the sample was heated up again to $100{ }^{\circ} \mathrm{C}$, and once again cooled down to $-100{ }^{\circ} \mathrm{C}$. In particular, the first two heating/cooling scans were performed to eliminate any thermal history effects. A Novocontrol Quatro Cryosystem was used to control the temperature by a dry nitrogen gas flow derived from liquid nitrogen. By correlating the amplitude and phase of the current passing through the dielectric sample capacitor with the applied AC voltage, the Alpha-Analyzer measured the complex impedance and capacity. Based on this data, the complex conductivity was calculated. The $\sigma_{\mathrm{dc}}$ was determined by a plateau in the conductivity $v s$. frequency plot in the usual way. ${ }^{23,24}$

\section{RESULTS AND DISCUSSION}

\section{A. Thermal analysis}

The [DEMA][OMs] phase transitions are revealed by DSC measurements (Fig. 1). The melting point is $37.7{ }^{\circ} \mathrm{C}$ and the freezing point is $14.0{ }^{\circ} \mathrm{C}$ (both are peak 
temperatures). The obtained melting and freezing points are in agreement with the values reported by other researchers. The melting point is significantly higher than the early reported value $\left(10.6^{\circ} \mathrm{C}\right),{ }^{12}$ which should be due to the high purity of [DEMA $][\mathrm{OMs}]$ we used. The entropy change, the enthalpy change and the melting or freezing point are correlated by Eq. (1):

$$
\Delta S=\Delta H / T
$$

where $\Delta S$ is the entropy change, $\Delta H$ the enthalpy change and $T$ the melting or freezing temperature in Kelvin $(\mathrm{K})$. The entropy changes at the melting and freezing points are calculated to be $18.2 \mathrm{~J} \mathrm{~K}^{-1} \mathrm{~mol}^{-1}$ and $-37.8 \mathrm{~J} \mathrm{~K}^{-1} \mathrm{~mol}^{-1}$, respectively.

Figure 1. DSC thermograms of [DEMA][OMs] measured at $10{ }^{\circ} \mathrm{C} \mathrm{min}^{-1}$ for both the heating and cooling scans. The melting point is $37.7^{\circ} \mathrm{C}$ and the freezing point is $14.0{ }^{\circ} \mathrm{C}$ (peak temperatures).

\section{B. Structural analysis}

Fig. 2 displays ${ }^{1} \mathrm{H}$ NMR spectrum of [DEMA][OMs] at ambient temperature. The resonance peaks a, b, c, d and e are associated with the diethylmethylammonium 
cation, while peak $\mathrm{f}$ is related to the methanesulfonate anion. More specifically, peak a indicates the resonance associated with the exchangeable proton $(\mathrm{N}-\mathrm{H})$; it is the origin of conductive protons, which has a chemical shift of $10.3 \mathrm{ppm}(\mathrm{s}, 1 \mathrm{H})$. Similarly, the chemical shifts of hydrogen atoms b, c, d, e and $\mathrm{f}$ are determined to be $3.24 \mathrm{ppm}(\mathrm{m}, 2 \mathrm{H}), 3.10 \mathrm{ppm}(\mathrm{m}, 2 \mathrm{H}), 2.83 \mathrm{ppm}(\mathrm{s}, 3 \mathrm{H}), 1.41 \mathrm{ppm}(\mathrm{t}, 6 \mathrm{H})$ and 2.82 ppm $(\mathrm{d}, 3 \mathrm{H})$, respectively. These results are in line with those reported by Martinelli et al. and Yarger et al.. ${ }^{19,20}$ It is noteworthy that the $\mathrm{N}-\mathrm{H}$ proton is coupled with its neighboring methyl and methylene protons due to the multiplet peaks. The methylene protons may be unisochronous because they have different chemical shifts of 3.24 ppm $(\mathrm{m}, 2 \mathrm{H})$ and $3.10 \mathrm{ppm}(\mathrm{m}, 2 \mathrm{H})$, respectively. This phenomenon can be explained by the reason that the motion of alkyl side chains of the diethylmethylammonium cation is hindered by ionic interactions between the cations and the anions at ambient temperature due to the rotational barrier around the $\mathrm{N}-\mathrm{C}$ bond. ${ }^{25}$ The ratio of the integrated areas of peaks a, b, c, d, e and f are $1.01: 2.00: 2.05: 2.99: 6.00: 3.01$, which agree very well with the hydrogen atomic ratio of [DEMA][OMs]. The small additional peak at around $7.30 \mathrm{ppm}$ is attributed to the residual signal of the solvent $\mathrm{CDCl}_{3}$. No other peaks were detected, implying the absence of detectable impurities. 
Figure 2. ${ }^{1} \mathrm{H}$ NMR spectrum of $[\mathrm{DEMA}][\mathrm{OMs}]$ at ambient temperature. Insets: the chemical structure of [DEMA][OMs] and partial enlargement of the spectrum. The symbols $a, b, c, d, e$ and f correspond to protons in different chemical environments. The small peak at around $7.30 \mathrm{ppm}$ is ascribed to the residual signal of the solvent $\left(\mathrm{CDCl}_{3}\right)$.

For the ${ }^{13} \mathrm{C}$ NMR spectrum of [DEMA][OMs] (see Fig. S1, Electronic Supplementary Information), the resonance peaks labeled with "a", "b" and "d" are associated with the cation, while the resonance peak marked with "c" is related to the methanesulfonate anion. The chemical shifts of carbon atoms a, b, c and d are confirmed to be $50.32 \mathrm{ppm}$ (s), $39.35 \mathrm{ppm}$ (s), $38.88 \mathrm{ppm}(\mathrm{s})$, and $9.13 \mathrm{ppm}(\mathrm{s})$, respectively. The ratio of the peak intensity matches the ratio of the number of carbon atoms for [DEMA][OMs]. The peak at around $77.20 \mathrm{ppm}$ is due to the residual signal of the $\mathrm{CDCl}_{3}$ solvent. These results confirm the purity of [DEMA][OMs].

\section{Vibrational analysis}

Fig. 3 shows FT-IR spectrum of [DEMA][OMs] at ambient temperature in the region between 250 and $3500 \mathrm{~cm}^{-1}$. At high wavenumbers, there are weak bands due to the low absorptivity of $\mathrm{C}-\mathrm{H}$ and $\mathrm{N}-\mathrm{H}$ groups. On the contrary, some sharp and strong peaks are found at low wavenumbers, which are mainly caused by the vibrations of the $[\mathrm{OMs}]$ anion, especially for the $\mathrm{C}-\mathrm{H}$ and $\mathrm{S}-\mathrm{O}$ stretching modes. The absence of $\mathrm{O}-\mathrm{H}$ stretching bands between 3400 and $3500 \mathrm{~cm}^{-1}$ demonstrates the extremely low water content. ${ }^{26,27}$ In addition, the broadening of the bands in the region of 2200-3200 $\mathrm{cm}^{-1}$ indicates a strong hydrogen-bonded network in 
$[\mathrm{DEMA}][\mathrm{OMs}] .^{28,29}$ In the case of ammonium-based PILs, this region is also a characteristic of ammonium structures and is associated with $\mathrm{N}-\mathrm{H}$ stretching. ${ }^{25,28,30}$

Figure 3. FT-IR spectrum of [DEMA][OMs] at ambient temperature.

The Raman spectrum of [DEMA][OMs] is recorded at ambient temperature between 250 and $3500 \mathrm{~cm}^{-1}$ (see Fig. S2, Electronic Supplementary Information). Most of Raman peaks have their equivalents in the FT-IR spectrum. For peaks at 2709, 2504 and $2360 \mathrm{~cm}^{-1}$ in FT-IR spectrum, it is difficult to find the corresponding peaks in the Raman spectrum, indicating that some infrared active vibrational modes are not Raman active. The observed FT-IR and Raman peaks and tentative vibrational assignments of [DEMA][OMs] are shown in Table I. ${ }^{25,28,30-37}$

Table I. Observed FT-IR and Raman peaks and tentative vibrational assignments of [DEMA][OMs]. The peak positions are given in $\mathrm{cm}^{-1}$ (as = antisymmetric; $\mathrm{s}=$ symmetric; $\mathrm{str}=$ stretching; bend $=$ bending; def $=$ deformation; wag $=$ wagging; roc $=$ rocking; twi $=$ twist )

Infrared bands and their assignments Raman bands and their assignments

Wavenumber $/ \mathrm{cm}^{-1}$ Assignments References $\quad$ Raman shifts $/ \mathrm{cm}^{-1}$ Assignments References




\begin{tabular}{|c|c|c|c|c|c|}
\hline 3010 & as $\mathrm{N}-\mathrm{H}$ str & 25,30 & 3010 & as $\mathrm{N}-\mathrm{H}$ str & 32 \\
\hline 2989 & as $\mathrm{CH}_{3}$ str & 31,32 & 2985 & as $\mathrm{CH}_{3}$ str & 32 \\
\hline 2938 & as $\mathrm{CH}_{2} \mathrm{str}$ & 31,32 & 2937 & as $\mathrm{CH}_{2} \mathrm{str}$ & 32 \\
\hline 2890 & $\mathrm{~s} \mathrm{CH}_{3} \mathrm{str}$ & 31,32 & 2894 & $\mathrm{~s} \mathrm{CH}_{3} \mathrm{str}$ & 32 \\
\hline 2841 & $\mathrm{~s} \mathrm{CH}_{2} \mathrm{str}$ & 31,32 & 2836 & $\mathrm{~s} \mathrm{CH}_{2} \mathrm{str}$ & 32 \\
\hline 2709 & $\mathrm{~s} \mathrm{~N}-\mathrm{H}$ str & 25,30 & & & \\
\hline 2504 & $\mathrm{~N}-\mathrm{H}$ str & 28 & & & \\
\hline 2360 & $\mathrm{~N}-\mathrm{H}$ str & 28 & & & \\
\hline 1481 & $\mathrm{CH}_{2}$ def & 32 & 1455 & $\mathrm{CH}_{2}$ def & 32 \\
\hline 1420 & as $\mathrm{CH}_{3}$ def & 33 & 1427 & as $\mathrm{CH}_{3} \mathrm{def}$ & 33 \\
\hline 1224 & as $\mathrm{SO}_{3} \mathrm{str}$ & 32 & 1233 & as $\mathrm{SO}_{3} \mathrm{str}$ & 33 \\
\hline 1151 & $\mathrm{C}-\mathrm{N}$ str & 32 & 1168 & $\mathrm{C}-\mathrm{N}$ str & 32 \\
\hline 1031 & $\mathrm{~s} \mathrm{SO}_{3} \mathrm{str}$ & 33 & 1038 & $\mathrm{~s} \mathrm{SO}_{3} \mathrm{str}$ & 33 \\
\hline 978 & $\mathrm{CH}_{3}$ roc & 33 & 978 & $\mathrm{CH}_{3}$ roc & 33 \\
\hline 885 & $\mathrm{C}-\mathrm{N}$ str & 32 & 886 & $\mathrm{C}-\mathrm{N}$ str & 32 \\
\hline 835 & $\mathrm{CH}_{2} \mathrm{roc}$ & 32 & 837 & $\mathrm{CH}_{2}$ roc & 32 \\
\hline 767 & $\mathrm{C}-\mathrm{S}$ str & 34 & 774 & $\mathrm{C}-\mathrm{S}$ str & 33 \\
\hline 550 & $\mathrm{SO}_{3}$ bend & 35 & 553 & $\mathrm{SO}_{3}$ bend & 37 \\
\hline 523 & as $\mathrm{SO}_{3}$ def & 35 & 525 & as $\mathrm{SO}_{3}$ def & 35 \\
\hline 458 & $\mathrm{SO}_{2}$ rock & 36 & 461 & $\mathrm{SO}_{2}$ rock & 37 \\
\hline 344 & $\mathrm{CH}_{3}$ wag & 33 & 339 & $\mathrm{CH}_{3}$ wag & 33 \\
\hline
\end{tabular}

\section{Conductivity analysis}

Fig. 4 shows 3D graphs of the real part of complex conductivity $\left(\sigma^{\prime}\right)$, the in-phase component of conductivity, as a function of frequency and temperature. Two jumps of $\sigma^{\prime}$ can be found at higher frequencies as the temperature increases to $40{ }^{\circ} \mathrm{C}$ (Fig. 4a) or decreases to $14{ }^{\circ} \mathrm{C}$ (Fig. 4b), respectively. The freezing point has a hysteresis of 
$26{ }^{\circ} \mathrm{C}$ compared with the melting point. Clearly, the conductivity jumps at phase transitions of melting or solidification. These two temperatures represent the melting and freezing points of [DEMA][OMs] and agree well with the DSC results.

Figure 4. Three-dimensional (3D) graphs of the real part of complex conductivity $\left(\sigma^{\prime}\right)$ as a function of frequency (from $0.421 \mathrm{~Hz}$ to $2.5 \mathrm{MHz}$ ) and temperature (between $-90{ }^{\circ} \mathrm{C}$ and $100{ }^{\circ} \mathrm{C}$ ) for the heating scan (a) and the cooling scan (b). 
In addition, taking the melting point or the freezing point as the demarcation, these curves can be divided into two parts. In the vicinity of the region below the melting point or the freezing point, the frequency-dependent conductivity curves show a plateau over a broad range of frequencies. At further lower temperatures, a plateau can be observed at higher frequencies. By contrast, in the region above the melting point or the freezing point, the frequency-dependent conductivity curves first exhibit a lower plateau at lower frequencies, which is due to the electrode polarization that results from interfacial effects. ${ }^{22-24}$ Then they gradually climb to a higher and flat plateau at higher frequencies. The boundary between these two plateaus shifts to higher frequencies as the temperature increases.

Figure 5. $\sigma_{\mathrm{dc}}$ of [DEMA][OMs] as a function of the reciprocal temperature recorded during heating and cooling scans. The reported conductivities of [DEMA][OMs] from Ref. 19 and 21 are also shown. ${ }^{19,21}$ Water contents: 98 ppm (this work); 7000 ppm (ref. 19); 2000 ppm (ref. 21).

$\sigma_{\mathrm{dc}}$ can be obtained by fitting the plateau of conductivity curves. Fig. 5 plots $\sigma_{\mathrm{dc}}$ as a function of the reciprocal temperature. Overall, the values of $\sigma_{\mathrm{dc}}$ during the 
heating and cooling processes overlap with each other except near the phase transition temperatures, and all curves are nonlinear. The $\sigma_{\mathrm{dc}}$ values of [DEMA][OMs] in the molten state are obviously lower than previously reported values because ionic conductivities are sensitive to water content (this work: 98 ppm; ref. 19: around 7000 ppm; ref. 21: around 2000 ppm), ${ }^{19,21}$ further confirming the high purity of the sample in this work. It has been shown that the water content (e.g. $>7000 \mathrm{ppm})^{4}$ has significant influence on the physicochemical properties of [DEMA]-based PILs. ${ }^{4,16}$ However, the impact of even far lower water contents on [DEMA][OMs] have so far been neglected. From the dielectric perspective, this reveals that even a seemingly negligible water content reported in the literature (e.g. about 7000 ppm or 2000 ppm) $)^{19,21}$ can still have non-negligible influence on the physicochemical properties (e.g. the $\left.\sigma_{\mathrm{dc}}\right)$ of protic ionic liquids, indicating the importance of reducing water content as much as possible for studying "intrinsic" properties of protic ionic liquids. In another way, [DEMA][OMs] with actually non-negligible water content (e.g. 2000 ppm) is in essence a "water-in-PIL" or "water-in-salt" system rather than a pure PIL.

Using extrapolation of the conductivity of [DEMA][OMs] as a function of added water at $25{ }^{\circ} \mathrm{C}$, Martinelli et al. ${ }^{16}$ estimated the $\sigma_{\mathrm{dc}}$ of the anhydrous [DEMA][OMs] at $25{ }^{\circ} \mathrm{C}$ to be $3-4 \mathrm{mS} \mathrm{cm}{ }^{-1}$. It is shown here that during the cooling process in the supercooled liquid state (Fig. 5) the $\sigma_{\mathrm{dc}}$ of pure [DEMA][OMs] is $2.98 \mathrm{mS} \mathrm{cm}^{-1}$ and $2.72 \mathrm{mS} \mathrm{cm}{ }^{-1}$ at $26{ }^{\circ} \mathrm{C}$ and $24{ }^{\circ} \mathrm{C}$, respectively. Thus the ionic conductivity at $25^{\circ} \mathrm{C}$ is determined to be $2.85 \mathrm{mS} \mathrm{cm}{ }^{-1}$ using interpolation method, which is in line with the extrapolated value, indicating again the high purity of our sample. 
Figure 6. (a) VFT fit curves and (b) the activation energies $\left(E_{\mathrm{a}}\right)$ for the ionic conduction process in $[\mathrm{DEMA}][\mathrm{OMs}]$ at temperatures above the melting/freezing point during the heating/cooling scan.

In order to further study the ionic conduction behavior, typical equations such as the Arrhenius equation and VFT law are used to fit the temperature dependence of the $\sigma_{\text {dc. }}$ For the data above the melting/freezing point, the VFT equation ${ }^{38-40}$ shown in Eq. (2) is used to describe the ionic conduction behavior, as the temperature dependence of $\sigma_{\mathrm{dc}}$ shows a significant deviation from Arrhenius behavior: 


$$
\sigma_{\mathrm{dc}}(T)=\frac{A}{\sqrt{T}} \exp \left(\frac{-B}{T-T_{0}}\right)
$$

where $A$ is proportional to the concentration of carrier ions, $B$ the pseudo activation energy for ion conduction, and $T_{0}$ the ideal glass transition temperature or the Vogel temperature, at which free volume or configurational entropy becomes zero and ionic conduction is completely frozen. ${ }^{41,42} A, B$ and $T_{0}$ are all adjustable parameters. The VFT fit curves are shown in Fig. 6a with the corresponding parameters listed in Table II. The $\sigma_{\mathrm{dc}}$ as a function of the reciprocal temperature obeys the VFT equation very well with excellent correlation coefficients $\left(R^{2}\right)$ (Table II). The fit value of $T_{0}$ is about $220 \mathrm{~K}$ for both processes. Because $\sigma_{\mathrm{dc}}$ follows the VFT equation and the ionic liquid is in the liquid state, the proton conduction is mainly governed by the vehicle mechanism. ${ }^{43-45}$ Interestingly, in the three cases of low water content (this work: 98 ppm; ref. 19: around 7000 ppm; ref. 21: around 2000 ppm), the ionic conduction in [DEMA][OMs] in the molten state all follows the vehicle mechanism, ${ }^{19,21}$ implying that the water content does not alter the proton conduction mechanism in the low water content region for [DEMA][OMs] in the molten state.

By performing partial differentiation of Eq. (2) in its logarithmic form with respect to $T$ and noting Eq. (3), temperature-dependent activation energies $\left(E_{\mathrm{a}}\right)$ for the transport process of ionic conduction can be obtained, yielding Eq. (4): ${ }^{46,47}$

$$
\begin{aligned}
& E_{a}=R T^{2}(\partial \ln \sigma / \partial T) \\
& E_{a}=R B T^{2} /\left(T-T_{0}\right)^{2}-R T / 2
\end{aligned}
$$

Clearly, $E_{\mathrm{a}}$ is a function of $T$ because $R, B$ and $T_{0}$ are constants in Eq. (4). Fig. $6 \mathrm{~b}$ shows the temperature dependence of $E_{\mathrm{a}}$ of ionic conduction of [DEMA][OMs]. The $E_{\text {a, }}$ which fall in the range between $10-50 \mathrm{~kJ} \mathrm{~mol}^{-1}$, increase rapidly with decreasing 
temperatures, which can be interpreted as due to the probability of ionic movement going to zero at $T_{0}$ rather than at $0 \mathrm{~K}$ according to the VFT equation (Eq. (2)). ${ }^{42}$ It is

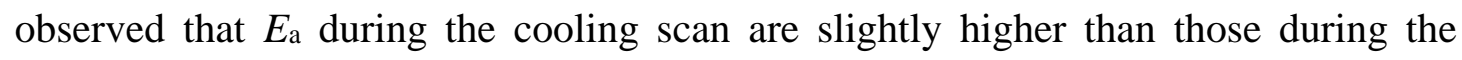
heating scan.

Figure 7. Arrhenius curve-fitting of the $\sigma_{\mathrm{dc}}$ of [DEMA][OMs] in the low temperature range between $-90{ }^{\circ} \mathrm{C}$ and $14{ }^{\circ} \mathrm{C}$. The temperature range from $14{ }^{\circ} \mathrm{C}$ to $40{ }^{\circ} \mathrm{C}$ during the heating scan is not taken for fitting as it is near the melting transition, showing a deviation from Arrhenius behavior which is also observed in some other protic organic salts. ${ }^{2,7}$

$E_{\mathrm{a}}$ in the solid (frozen) state is calculated using the Arrhenius equation (Eq. (5)):

$$
\sigma_{\mathrm{dc}}(T)=\sigma_{0} \exp \left(-\frac{E_{a}}{R T}\right)
$$

where $\sigma_{0}$ is the pre-exponential factor in $\mathrm{S} \mathrm{cm}^{-1}, E_{\mathrm{a}}$ the activation energy in $\mathrm{kJ} \mathrm{mol}^{-1}$, and $R$ the universal gas constant. ${ }^{2}$ Both the heating and cooling curves can be divided into two parts: from $-90{ }^{\circ} \mathrm{C}$ to $-50{ }^{\circ} \mathrm{C}$ and then from $-50{ }^{\circ} \mathrm{C}$ to $14{ }^{\circ} \mathrm{C}$ (heating scan); from $14{ }^{\circ} \mathrm{C}$ to $-50{ }^{\circ} \mathrm{C}$ and subsequently from $-50{ }^{\circ} \mathrm{C}$ to $-90{ }^{\circ} \mathrm{C}$ (cooling scan). These 
four parts are fitted separately.

Table II. Fit results of [DEMA][OMs] for both the heating and cooling processes.

\begin{tabular}{llllllll}
\hline Processes & $T /{ }^{\circ} \mathrm{C}$ & $A /\left(\mathrm{S} \mathrm{K}^{1 / 2} \mathrm{~cm}^{-1}\right)$ & $B / \mathrm{K}$ & $T_{0} / \mathrm{K}$ & $\sigma_{0} /\left(\mathrm{S} \mathrm{cm}^{-1}\right)$ & $E_{\mathrm{a}} /\left(\mathrm{kJ} \mathrm{mol}^{-1}\right)$ & $R^{2 a}$ \\
\hline \multirow{4}{*}{ Heating } & {$[+40,+100]$} & 2.03 & 286 & 221 & - & - & 0.9999 \\
& {$[-50,+14]$} & - & - & - & $2.18 \times 10^{8}$ & 70.5 & 0.9991 \\
& {$[-90,-50]$} & - & - & - & $7.09 \times 10^{14}$ & 98.7 & 0.9993 \\
& {$[+100,+14]$} & 2.38 & 301 & 220 & - & - & 0.9999 \\
Cooling & {$[+14,-50]$} & - & - & - & $1.96 \times 10^{9}$ & 75.0 & 0.9999 \\
& {$[-50,-90]$} & - & - & - & $1.55 \times 10^{15}$ & 100 & 0.9991 \\
${ }^{a} R^{2}$ : correlation coefficient for VFT or Arrhenius fit results. & & \\
\hline
\end{tabular}

The Arrhenius fit results are shown in Table II and Fig. 7. The excellent correlation coefficients indicate the curves obey the Arrhenius equation well. Interestingly, the temperatures of the crossover points that divide the respective heating or cooling scan into two parts are both $-50{ }^{\circ} \mathrm{C}$, which agrees well with the calculated $T_{0}$ (about $-53{ }^{\circ} \mathrm{C}$ ) obtained from the VFT curve-fitting (Table II). In fact, at the temperature of calculated $T_{0}, \sigma_{\mathrm{dc}}$ is around $2.5 \times 10^{-9} \mathrm{~S} \mathrm{~cm}^{-1}$. To some degree, it confirms that at $T_{0}$ the ionic conduction is frozen due to theoretically zero free volume. ${ }^{41,42}$ The Grotthuss (proton hopping mechanism) and the vehicle mechanisms have been proposed to explain the proton conduction in solid compounds. ${ }^{48,49}$ Below the melting point and freezing point it is difficult to move freely for charge carriers. Additionally, the curves follow the Arrhenius equation well. Therefore, it could be inferred that the proton hopping mechanism is the underlying main proton conduction mechanism in the solid (frozen) state (e.g. from $-90{ }^{\circ} \mathrm{C}$ to $14{ }^{\circ} \mathrm{C}$ ).

\section{CONCLUSIONS}

Diethylmethylammonium methanesulfonate ([DEMA][OMs]), a typical protic ionic liquid, has been systematically studied for its thermal, structural, spectroscopic, 
and ionic conduction properties under anhydrous conditions. The purity of [DEMA][OMs] is confirmed by NMR and FT-IR spectra as well as the $\sigma_{\mathrm{dc}}$. The resonance peaks of ${ }^{1} \mathrm{H}-\mathrm{NMR}$ and ${ }^{13} \mathrm{C}-\mathrm{NMR}$ spectra are identified, and the vibrational bands of FT-IR and Raman spectra are tentatively assigned. In addition, the melting point and the freezing point obtained by DSC agree well with the values detected by BDS. Based on BDS analysis, the freezing point shows a hysteresis of $26{ }^{\circ} \mathrm{C}$ compared with the melting point. Furthermore, the ionic conduction above the melting/freezing point obey the VFT equation well and proton conduction is thus dominated by the vehicle mechanism. It is found that the water content does not change the proton conduction mechanism in the low water content region of [DEMA][OMs] in the molten state. However, the previously reported low water contents are found to have non-negligible influence on the physicochemical properties (e.g. the $\sigma_{\mathrm{dc}}$ ) of [DEMA][OMs], implying the importance of reducing water content as much as possible for the study of "intrinsic" properties of protic ionic liquids. The ionic conduction below the melting/freezing point could be fitted by the Arrhenius equation and the proton conduction is presumed to follow the proton-hopping mechanism. The findings are expected to provide some insights for the development of fuel cell electrolytes based on protic ionic liquids.

\section{SUPPLEMENTARY MATERIAL}

See the supplementary material for ${ }^{13} \mathrm{C}$ NMR and Raman spectra of [DEMA $][\mathrm{OMs}]$ at ambient temperature.

\section{ACKNOWLEDGMENTS}


H. Pan acknowledges China Scholarship Council (CSC) for a doctoral scholarship (Grant No.: 201808370196). Funding from the Research Foundation Flanders (FWO) (project No.: G0B3218N), the National Natural Science Foundation of China (project No.: 21776120) and Natural Science Foundation of Fujian Province, China (No.: 2018J01433) is acknowledged. T. Putzeys acknowledges funding by FWO (12Y6919N).

\section{DATA AVAILABILITY}

The data that support the findings of this study are available from the corresponding author upon reasonable request.

\section{REFERENCES}

1. M. S. Miran, M. Hoque, T. Yasuda, S. Tsuzuki, K. Ueno, and M. Watanabe, Phys. Chem. Chem. Phys. 21, 418 (2019).

2. J. Luo, A. H. Jensen, N. R. Brooks, J. Sniekers, M. Knipper, D. Aili, Q. Li, B. Vanroy, M. Wübbenhorst, F. Yan, L. Van Meervelt, Z. Shao, J. Fang, Z.-H. Luo, D. E. De Vos, K. Binnemans, and J. Fransaer, Energy Environ. Sci 8, 1276 (2015).

3. D. E. Smith, and D. A. Walsh, Adv. Energy Mater. 9, 1900744 (2019).

4. K. Wippermann, J. Giffin, S. Kuhri, W. Lehnert, and C. Korte, Phys. Chem. Chem. Phys. 19, 24706 (2017).

5. P. Jannasch, J. Rehmen, D. Evans, and C. Karlsson, J. Phys. Chem. C 123, 23427 (2019).

6. N. Yaghini, I. Abdurrokhman, M. Hasania, and A. Martinelli, Phys. Chem. Chem. 
Phys. 20, 22980 (2018).

7. X. Chen, H. Tang, T. Putzeys, J. Sniekers, M. Wubbenhorst, K. Binnemans, J. Fransaer, D. E. De Vos, Q. Li, and J. Luo, J. Mater. Chem. A 4, 12241 (2016).

8. J. Luo, O. Conrad, and I. F. J. Vankelecom, J. Mater. Chem. A 1, 2238 (2013).

9. J. Luo, T. V. Tan, O. Conrad, and I. F. J. Vankelecom, Phys. Chem. Chem. Phys. 14, $11441(2012)$.

10. Z. Zhu, X. Yan, H. Tang, H. Cai, M. Pan, H. Zhang, and J. Luo, J. Power Sources 351, 138 (2017).

11. W. Xu, and C. A. Angell, Science 302, 422 (2003).

12. H. Nakamoto, and M. Watanabe, Chem. Commun. 2539 (2007).

13. C. Römich, N. C. Merkel, A. Valbonesi, K. Schaber, S. Sauer, and T. J. S. Schubert, J. Chem. Eng. Data 57, 2258 (2012).

14. N. C. Merkel, C. Römich, R. Bernewitz, H. Künemund, M. Gleiß, S. Sauer, T. J. S. Schubert, G. Guthausen, and K. Schaber, J. Chem. Eng. Data 59, 560 (2014).

15. N. Merkel, C. Weber, M. Faust, and K. Schaber, Fluid Phase Equilibr. 394, 29 (2015).

16. N. Yaghini, M. N. Garaga, and A. Martinelli, Fuel Cells 16, 46 (2016).

17. M. Atilhan, B. Anaya, R. Ullah, L. T. Costa, and S. Aparicio, J. Phys. Chem. C 120, 17829 (2016).

18. M. N. Garaga, M. Persson, N. Yaghinia, and A. Martinelli, Soft Matter 12, 2583 (2016).

19. M. N. Garaga, L. Aguilera, N. Yaghini, A. Matic, M. Perssonc and A. Martinelli, 
Phys. Chem. Chem. Phys. 19, 5727 (2017).

20. S. K. Davidowski, F. Thompson, W. Huang, M. Hasani, S. A. Amin, C. Austen Angell, and J. L. Yarger, J. Phys. Chem. B 120, 4279 (2016).

21. J. L. Lebga Nebane, S. E. Rock, J. Franclemont, D. Roy, and S. Krishnan, Ind. Eng. Chem. Res. 51, 14084 (2012).

22. F. Kremer, and A. Schonhals, Broadband Dielectric Spectroscopy, Springer, Berlin, (2003).

23. M. Wübbenhorst, and J. van Turnhout, J. Non-Cryst. Solids 305, 40 (2002).

24. J. Leys, M. Wübbenhorst, C. Preethy Menon, R. Rajesh, J. Thoen, C. Glorieux, P. Nockemann, B. Thijs, K. Binnemans, and S. Longuemart, J. Chem. Phys. 128, 064509 (2008).

25. M. Kazuki, H. Syu, Y. Tomoaki, and S. Kazuhisa, B. Chem. Soc. Jpn. 83, 328 (2010).

26. J. Luo, O. Conrad, and I. F. J. Vankelecom, J. Mater. Chem. 22, 20574 (2012).

27. J. P. Belieres, and C. A. Angell, J. Phys. Chem. B 111, 4926 (2007).

28. J. Luo, J. Hu, W. Saak, R. Beckhaus, G. Wittstock, I. F. J. Vankelecom, C. Agert, and O. Conrad, J. Mater. Chem. 21, 10426 (2011).

29. A. Elaiwi, P. B. Hitchcock, K. R. Seddon, N. Srinivasan, Y. M. Tan, T. Welton, and J. A. Zora, J. Chem. Soc., Dalton Trans. 3467 (1995).

30. E. S. Stoyanov, K. C. Kim, and C. A. Reed, J. Am. Chem. Soc. 128, 8500 (2006).

31. J. Pacansky, W. Koch, and M. D. Miller, J. Am. Chem. Soc. 113, 317 (1991).

32. A. L.Verma, Spectrochim. Acta, 27, 2433 (1971). 
33. J. H. R. Clarke, and L. A. Woodward, Trans. Faraday Soc. 62, 2226 (1966).

34. E. Davies, Y. Huang, J. B. Harper, J. M. Hook, D. S. Thomas, I. M. Burgar, and P. J. Lillford, Int. J. Food Sci. Tech. 45, 2502 (2010).

35. D. H. Johnston and D. F. Shiver, Inorg. Chem. 32, 1045 (1993).

36. S. P. Gejji, K. Hermansson, and J. Lindgren, J. Phys. Chem. 97, 6986 (1993).

37. J. R. Durig, L. Zhou, T. Schwartzt, and T. Gounev, J. Raman Spectrosc. 31, 193 (2000).

38. H. Vogel, Phys. Z. 22, 645 (1921).

39. G. S. Fulcher, J. Am. Ceram. Soc. 8, 339 (1925).

40. G. Tammann, and W. Z. Hesse, Z. Anorg. Allg. Chem. 156, 245 (1926).

41. S. Seki, M. A. B. H. Susan, T. Kaneko, H. Tokuda, A. Noda, and M. Watanabe, J. Phys. Chem. B 109, 3886 (2005).

42. C. A. Angell, J. Electrochem. Soc. 112, 1224 (1965).

43. A. Noda, M. A. B. H. Susan, K. Kudo, S. Mitsushima, K. Hayamizu, and M. Watanabe, J. Phys. Chem. B 107, 4024 (2003).

44. W. Münch, K. D. Kreuer, W. Silvestri, J. Maier, and G. Seifert, Solid State Ionics 145, 437 (2001).

45. J. Lin, L. Wang, T. Zinkevich, S. Indris, Y. Suo, and C. Korte, Phys. Chem. Chem. Phys. 22, 1145 (2020).

46. J. R. Sanders, E. H. Ward, and C. L. Hussey, J. Electrochem. Soc. 134, 325 (1986). 
47. K. Wippermann, J. Wackerl, W. Lehnert, B. Huber, and C. Korte, J. Electrochem. Soc. 163, F25 (2016).

48. K. D. Kreuer, Chem. Mater. 8, 610 (1996).

49. P. Colomban, Proton Conductors: Solids, Membranes and Gels-Materials and Devices, Cambridge University Press, Cambridge (1992). 


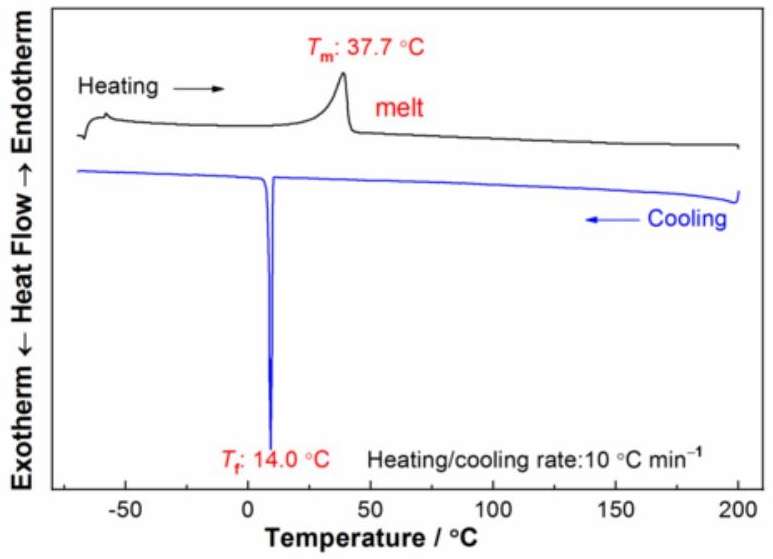




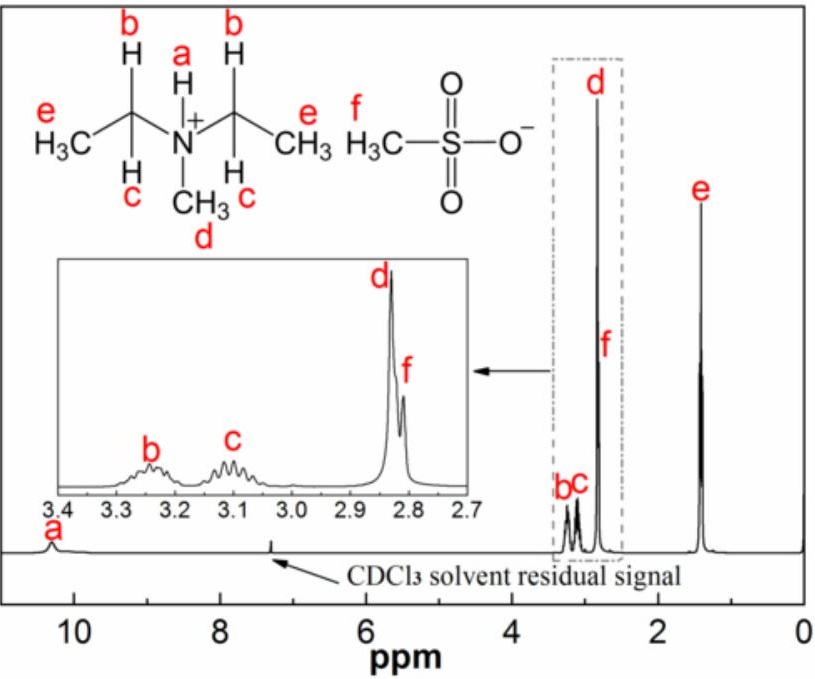




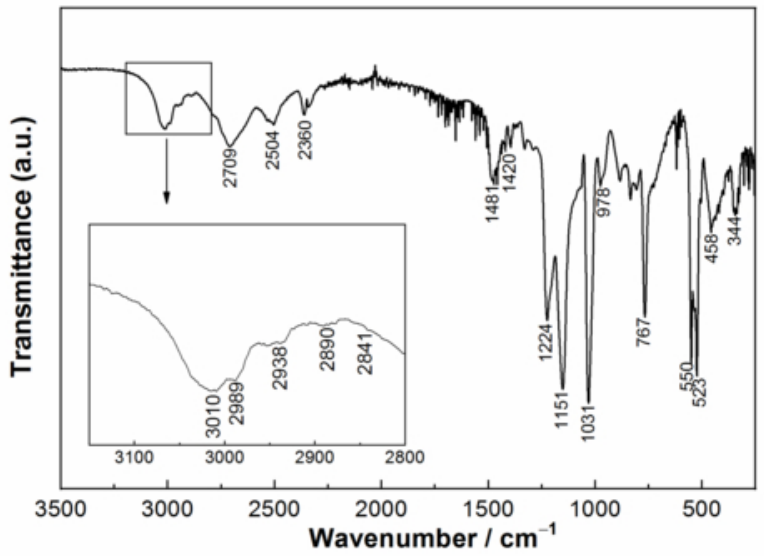




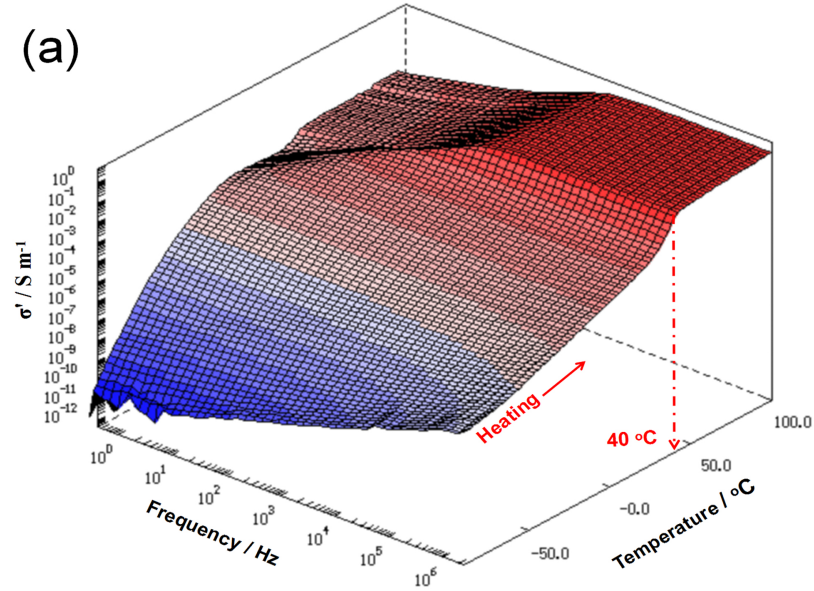




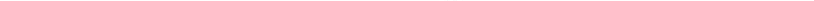




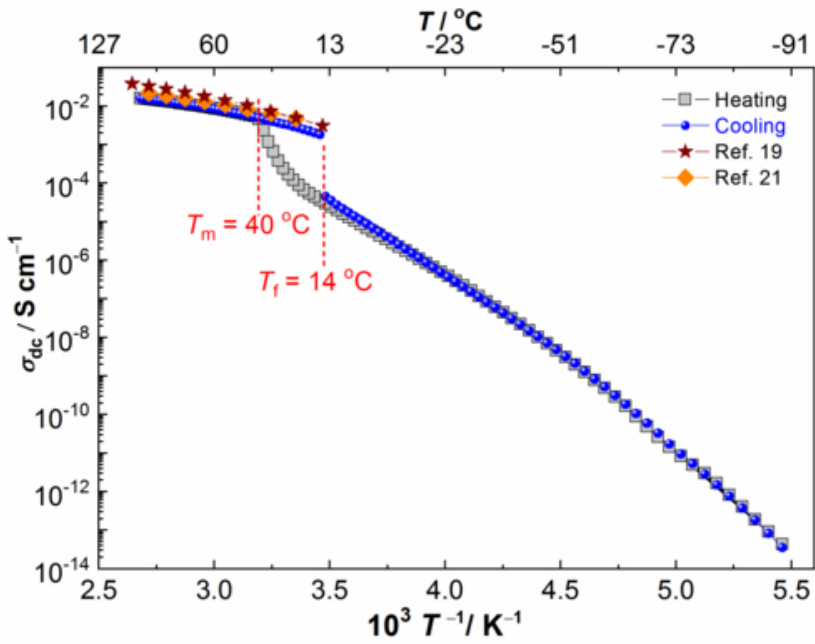




\section{$\mathrm{T} /{ }^{\circ} \mathrm{C}$}

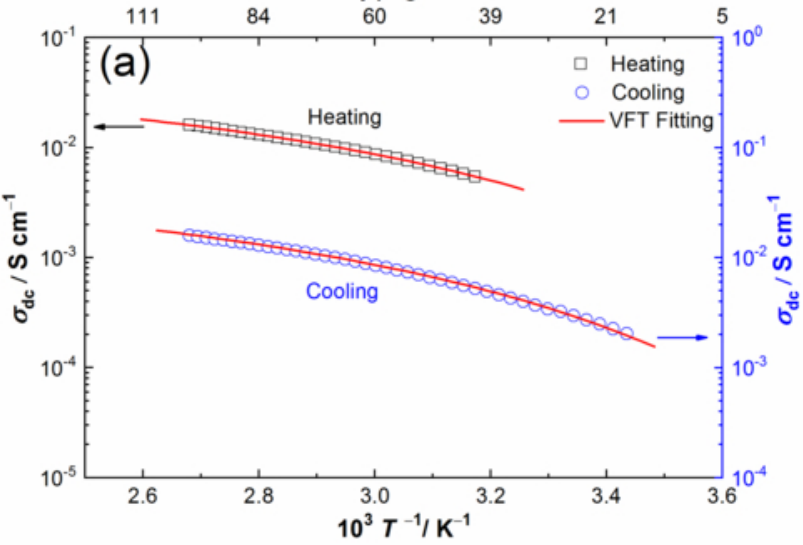




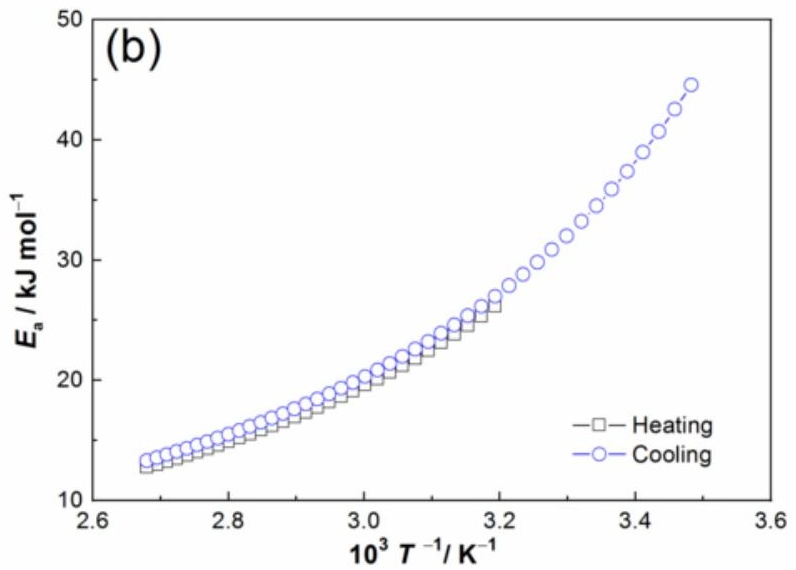


$T /{ }^{\circ} \mathrm{C}$

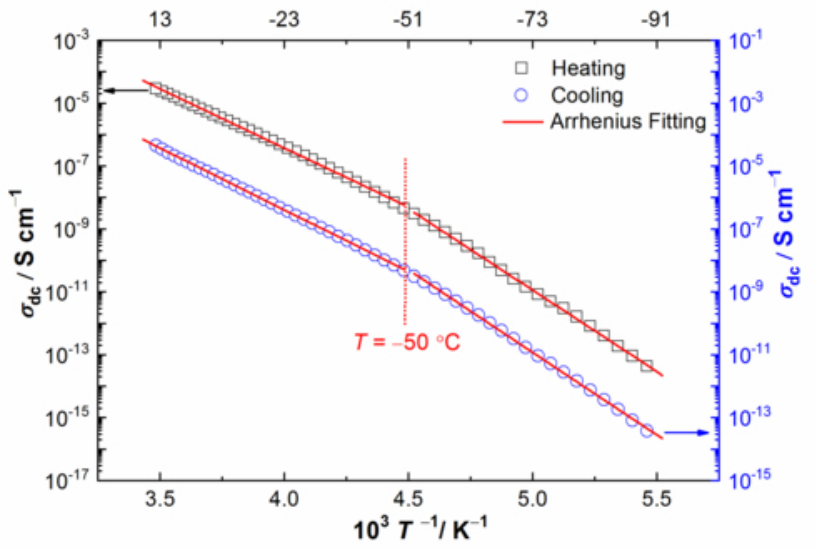

